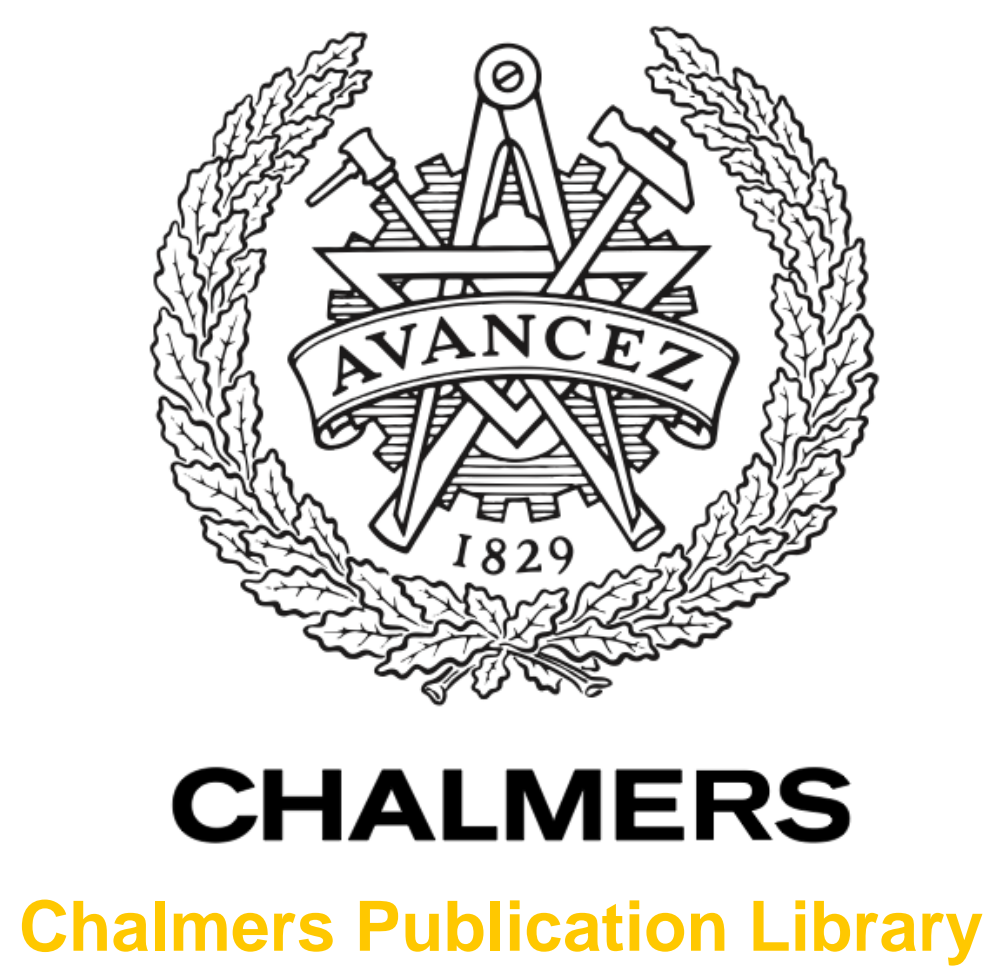

Exploring problems related to the materials planning user environment

This document has been downloaded from Chalmers Publication Library (CPL). It is the author's version of a work that was accepted for publication in:

International Journal of Production Economics

Citation for the published paper:

Jonsson, P. (2008) "Exploring problems related to the materials planning user environment". International Journal of Production Economics, vol. 113(1), pp. 383-400.

Downloaded from: http://publications.lib.chalmers.se/publication/69865

Notice: Changes introduced as a result of publishing processes such as copy-editing and formatting may not be reflected in this document. For a definitive version of this work, please refer to the published source. Please note that access to the published version might require a subscription. 
Full reference: Jonsson, P. (2008). Exploring problems related to the materials planning user environment. International Journal of Production Economics. 113(1): 383-400.

\title{
Exploring problems related to the materials planning user environment
}

\author{
Patrik Jonsson ${ }^{1}$ \\ Chalmers University of Technology, Sweden
}

\begin{abstract}
This paper explores the existence of various user environment problems (i.e. problems related to the planning organization, basic planning data, software support, education and knowledge) and explains the impact of user environment problems on the perceived planning performance of different materials planning methods (MRP, re-order point, kanban, run-out time and periodic review methods). It is based on a survey of 153 manufacturing and 53 distributing companies in Sweden. Four distinct clusters of user environments are identified. It is shown how different materials planning methods perform differently in various user environments.
\end{abstract}

Keywords: inventory management, materials requirements planning, organizational issues, productivity

\section{Introduction}

Materials planning methods differ in applicability due to the existing planning environment, i.e. depending on the demand, product and process characteristics (e.g. Krajewski et al., 1987, Berry and Hill, 1992, Jonsson and Mattsson, 2003). The planning performance is not only a result of which method is used and in which planning environment it is applied. The user environment, i.e. the software support available in the ERP system or a similar information system supporting the planning function (hereafter, the term ERP is used also for similar planning information systems), the quality of the planning information, and how actively the planning personnel actually are working with designing and using the respective method, should also have important impact on the planning performance.

The user environment can impact the planning performance directly, but also indirectly according to how easy it is to maintain planning parameters in the ERP system and the knowledge, authority and available time for the planning personnel to actively work with the ERP system and apply the respective materials planning method in practical usage.

However, the role of these user environment issues may differ between materials planning methods. The re-order point, fixed-order interval, and kanban methods could be used manually as visual methods, without a data base and calculations in ERP systems. MRP is always highly dependent on the quality of the planning information and the ERP.

\footnotetext{
${ }^{1}$ Patrik Jonsson, Professor Operations \& Supply Chain Management

Division of logistics and transportation

Department of technology management and economics

41296 Gothenburg

Sweden

E-mail: patrik.jonsson@chalmers.se

Ph: +46 317721336
} 
Full reference: Jonsson, P. (2008). Exploring problems related to the materials planning user environment. International Journal of Production Economics. 113(1): 383-400.

Several previous studies have focused on the importance of variables related to user environment when implementing ERP systems (e.g. Sum et al., 1999; Petroni, 2002, Sun et al., 2005), but not on their role in the operational use of individual materials planning methods, with or without support by ERP systems. Hence, the focus of this study is on this "user environment" and how user environment problems impact the materials planning performance.

The objective of this study is to explore what kind of user environment problems that exist in Swedish industries (i.e. problems related to the software support, education and knowledge, planning organization, and basic data quality) and explain the impact of the user environment on the perceived planning performance of the materials planning methods - MRP, re-order point, fixed-order interval, run-out time planning and kanban methods. Based on survey data of Swedish manufacturing and distribution companies, the analysis follows five steps: (1) developing an empirical taxonomy of user environments, (2) comparing company sizes and planning environment characteristics between user environment cluster groups, (3) describing what materials planning methods are used and how they are used in different user environments, (4) describing the perceived planning performance of materials planning methods in various user environments, and (5) explaining the characteristics of user environments among companies with high and low perceived planning performance, respectively.

\section{Theory and propositions}

\subsection{The user environment}

The user environment is the operational environment surrounding the material planner in his/her daily planning activities. Based on previous research about MRP and ERP implementation and usage (e.g. Plenert, 2002) we identify four dimensions of the user environment: the software support, the education and knowledge of the planner, the organizational design and function of the planning activities, and the quality of the basic data used as input in the materials planning methods. The dimensions are motivated and defined below.

The software support includes investment in enterprise resource planning (ERP), advanced planning systems (APS), or similar information system, with support for materials planning. Software support is a necessity for MRP usage. Even though several studies have explained the positive performance effect of investing in advanced manufacturing technology in general (e.g. Boyer et al., 1997), and in ERP software in particular (Braglia and Petroni, 1999), there are several problems involved in efficiently and effectively using ERP software. Examples are the high complexity of the system, lack of training and knowledge among managers and personnel, low data accuracy, and lack of support from the software vendor, especially among small firms (Turnipseed et al., 1992; Petroni, 2002). Software support is especially important in MRP environments.

Several studies have shown that the organizational infrastructure, for example, characterized by educated, trained, motivated and empowered personnel, is of particular importance in order to make technology and software investments successful. Boyer et al. 
Full reference: Jonsson, P. (2008). Exploring problems related to the materials planning user environment. International Journal of Production Economics. 113(1): 383-400.

(1997), for instance, studied the interaction between the adoption of general advanced manufacturing technologies, including ERP, and investments in an infrastructure of direct labor with high technical competence and high skill level throughout the organization. They concluded that firms which invested in both AMTs and the infrastructure performed better than firms which only invested in one or the other. Similar findings are presented by, for example, Wong and Ngih (1997) and Jonsson (2000).

Several studies on ERP implementation conclude that top management's support together with personnel education and training are of vital importance for successfully implementing an ERP system, but also for running the system after implementation. The role of top management is to invest in education, spend time with people and assume a long-term perspective for successfully using the MRP module in the ERP or APS system. The importance of education and training, and for companies to actively manage the educational process, has especially been shown in several studies (Salaheldin and Francis, 1998; Sum et al., 1999; Petroni, 2002; Muscatello et al., 2003; Sun et al, 2005; $\mathrm{Yu}, 2005$, Bozarth, 2006). The level of training and education provided becomes more critical as the size of the company increases, since users need to better understand their roles and the impacts of their actions on downstream users and other functional areas (Sum et al., 1999). Education is a cornerstone in most ERP implementations, but is often centered on computer/system operations, rather than on understanding the manufacturing planning and control concepts that the software system is supposed to support. The study by $\mathrm{Yu}(2005)$ identifies this problem and emphasizes the importance of continuous education and training in manufacturing planning and control practices in order to successfully use the planning support available in the ERP system. Education and training among the personnel involved in the manufacturing planning and control processes should be important even if the materials planning is conducted without support from an ERP system. Jonsson and Mattsson (2006) conclude that the general knowledge of planning and control methods in industry is rather low, and that it most likely needs to be improved in order to achieve better use and performance of the planning methods.

The structure and functioning of the planning organization are emphasized in sales and operations planning (Ling and Goddard, 1988) and supply chain forecasting and planning (e.g. Stank et al., 1999) processes. There, the focus is on cross-functional teams and creating global visibility and event-based planning (Stadtler and Kilger, 2005) when making planning decisions. In the detailed materials planning, using MRP or re-order point related methods, the focus is rather on local efficiency. The organizational focus should be on developing an organization where the planner has the knowledge, authority and enough time to maintain the planning parameters in the ERP system and make use of its functionality in appropriate ways when making materials planning decisions. This is especially true for MRP methods. In pure JIT and re-order point environments, the organizational design may have less importance and companies may even be successful without a planning department.

In addition to appropriate software support, education and knowledge among the personnel in manufacturing planning and control practices, management commitment, and appropriate planning organization where the personnel do not have too many items to 
Full reference: Jonsson, P. (2008). Exploring problems related to the materials planning user environment. International Journal of Production Economics. 113(1): 383-400.

control, it is important to ensure high basic data accuracy. The accuracy of inventory and lead-time records is especially critical in MRP (Covin, 1981; White et al.; 1982, Browne, 1996; Sum et al., 1999; Petroni, 2002) and particularly in larger companies (Sum et al., 1999), but also has significant performance impact when using computerized re-order point methods. The inventory accuracy is affected by the cycle counting strategy and use of automatic data capture when registering inventory transactions. The lead-time accuracy is affected by the way it is determined and the frequency of reviewing the parameter in the ERP system.

In accordance with the above discussion, we propose that the characteristics of the userenvironment affect the possibility for the materials planning methods to work properly. Thus, they should impact the materials planning performance, both in terms of the perceived user friendliness and the operational performance.

\subsection{Controlling variables}

The materials planning performance could be affected by other than the user environment variables. Here, the following four types of such control variables are defined: 1) company size, 2) type of operation, 3) operational materials planning strategy, 4) planning environment characteristics.

It is reasonable to believe that the perceived user environment problems differ between companies of various sizes and in companies conducting materials planning in different types of operations. In small companies, for example, organizational design issues may be of less importance than in larger companies with more complex material flows and relationships (e.g. Sum et al., 1999). Materials planning could also be expected to be easier in companies controlling inventories of finished products (distribution operations) or spare parts, compared to manufacturing companies controlling more complex manufacturing flows and purchase of components and raw materials. We, therefore, propose that company size and type of operation affect the possibility for the materials planning methods to work properly. Thus, the company size and type of operation should impact the materials planning performance.

The ways individual materials planning methods are designed and used also have planning performance impact. Jonsson and Mattsson (2007), for example, showed that higher re-order point method performance was achieved when determining the re-order point as the demand during the lead-time plus a safety stock, compared to determining it as a fixed quantity and frequently reviewing this order point quantity. Their study also showed that accurate lead-times and safety stocks are two of the most critical parameters to determine and review for achieving high MRP performance. The way materials planning methods are designed and used are here called operational materials planning strategies. According to the above discussion, we propose that the operational materials planning strategies impact the materials planning performance.

Materials planning methods also differ in applicability due to the planning environment on hand. MRP works reasonably well in all manufacturing companies irrespective of the specific planning environment (e.g. Newman and Sridharan, 1992). Its relative strength lies in environments with complex standardized products or product options, long 
Full reference: Jonsson, P. (2008). Exploring problems related to the materials planning user environment. International Journal of Production Economics. 113(1): 383-400.

manufacturing lead-times, and items with time-varying and lumpy demand (e.g. Plenert, 1999; Jonsson and Mattsson, 2003). The re-order point method is basically designed for items with independent demand. Therefore, it cannot be expected to perform very effectively regardless of the planning environments, especially not in environments characterized by complex product structures and long manufacturing lead-times. The reorder point method can, however, be reasonably effectively used the more standardized the components in the products are, the longer life cycles they have, and the more stable the demand is (e.g. Jacobs and Whybark, 1992; Newman and Sridharan, 1995; Jonsson and Mattsson, 2003). The same arguments apply to the fixed-order interval and runouttime planning methods, which basically are re-order point types of methods. The relative strength of kanban is greatest in environments with an even and steady demand, and where the products have simple and flat bills of material (e.g. Giauque and Sawaya, 1992), short lead-times and small order quantities (e.g. Newman and Sridharan, 1992). Even though some methods could perform reasonably well in "difficult" environments, all methods can be expected to perform worse the more uncertain and complex the demand, products and material flows are (e.g. Newman and Sridharan, 1992, Jonsson and Mattsson, 2003). We, therefore, propose that the planning environment affects the possibility for the materials planning methods to work properly. Thus, the planning environment should impact the materials planning performance. Figure 1 summarizes the examined variables and proposed relationships between the user environment characteristics, company size, type of operation, materials planning application, planning environment characteristics and perceived materials planning performance.

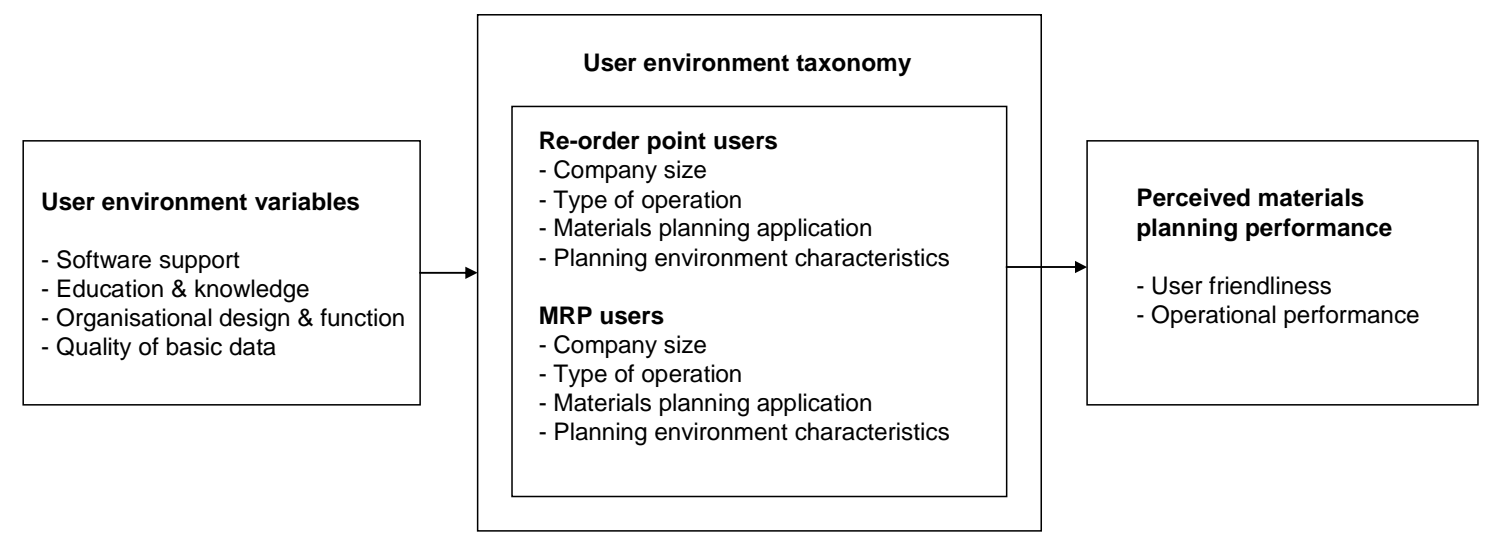

Figure 1. User environment, controlling variables and perceived materials planning performance relationships 
Full reference: Jonsson, P. (2008). Exploring problems related to the materials planning user environment. International Journal of Production Economics. 113(1): 383-400.

\section{Methodology}

\subsection{Selection and Data Collection}

Data collection was made by a web-based survey. E-mails about participation in the survey were sent to 573 member companies of the Swedish Production and Inventory Management Society (PLAN), an affiliate of APICS. Of these 573 companies, 153 responded, giving a response rate of $31 \%$. We expected most PLAN companies to be in manufacturing and thus to use materials planning methods for controlling stocks of purchased and manufacturing items. In order to include companies using materials planning methods in distribution operations, the survey was also sent to logistics managers at all Swedish wholesaling companies with more than 20 employees. Addresses were provided by the Swedish postal service: 469 surveys were sent out and 53 usable responses were received, giving a response rate of $11 \%$. The reason for including wholesaling companies was to allow for comparison of user environments between manufacturing and distribution companies. Most previous materials planning studies focus on manufacturing companies. Because several data were perceived data, it was important to make sure that the respondents hold more or less similar positions so that their differing perspectives did not create another source of variation. Therefore, PLAN members with logistics manager, production manager or logistics development manager positions and logistics managers in wholesaling companies where selected as respondents. About half of the respondents were from metal fabricating companies and more than half were large companies (Table 1). Manufacturing companies with a turnover below SEK 100 million (equivalent to about 12 million Euro) or with less than 50 employees were defined as small. Those with a turnover between SEK 100 million and SEK 300 million and with more than 50 employees were considered medium-sized companies.

Table 1. Characteristics of respondents

\begin{tabular}{|c|c|c|c|c|}
\hline & \multicolumn{2}{|c|}{$\begin{array}{c}\text { Manufacturing } \\
\text { companies }\end{array}$} & \multicolumn{2}{|c|}{ Distribution operations } \\
\hline & $\begin{array}{l}\text { Number of } \\
\text { responses }\end{array}$ & Percentage & $\begin{array}{l}\text { Number of } \\
\text { responses }\end{array}$ & Percentage \\
\hline $\begin{array}{l}\text { Size: } \\
\text { Small \& Medium sized } \\
\text { Large sized }\end{array}$ & $\begin{array}{l}45 \\
103\end{array}$ & $\begin{array}{l}30 \% \\
70 \% \\
100 \% \\
\end{array}$ & $\begin{array}{l}22 \\
27\end{array}$ & $\begin{array}{l}45 \% \\
55 \% \\
100 \% \\
\end{array}$ \\
\hline
\end{tabular}

Note: Chi-square 3.44 (sign $\mathrm{p}<0.07)$

Generally speaking, PLAN members are distributed across manufacturing industries according to the average for Swedish manufacturing (i.e. with about half of the companies in the metal fabricating sector). A reason for sending the questionnaire to PLAN members was that they were likely to have an interest in manufacturing planning and be familiar with the terminology used in the survey. Membership of PLAN is personal. Therefore, we did not expect the studied companies to be more advanced users of planning methods compared to the average for Swedish manufacturing, only that the respondents were more aware of the manufacturing planning and control area compared 
Full reference: Jonsson, P. (2008). Exploring problems related to the materials planning user environment. International Journal of Production Economics. 113(1): 383-400.

to the average. For the wholesaling companies, the situation is different. In this case, the survey was therefore addressed to logistics managers.

\subsection{The Survey Instrument}

There are five types of measures in this study. The first measures the perceived user environment problems. The second measures the use of the following materials planning methods: re-order point, periodic review, run-out time, MRP and kanban. The third measures operational MRP and re-order point strategies with proposed impact on the perceived planning performance. The fourth measures the general planning environment and the fifth measures the perceived performance of the planning methods used. The classifications used and criteria measured follow the general manufacturing planning and control definitions (e.g. Vollmann et al., 2005).

The user environment is measured for seven different items, each representing one variable. The seven variables are (complete measures, see Appendix A):

1. Software support - The software support for inventory management, available in the ERP system.

2. Education and knowledge - The level of education and knowledge for materials planning issues.

3. Management commitment - The management commitment to materials planning issues.

4. Organizational design - The structure of the materials planning organization.

5. Available planning time - The available time for materials planning, aims being that it is not too short and that each planner need not take care of too many items.

6. Inventory account accuracy - The inventory accuracy in the basic data file in the ERP system.

7. Lead-time precision - The lead-time precision in the basic data file in the ERP system.

In one analysis, the items "Management commitment”, “Organizational design” and "Available planning time" were exchanged for the variable "Organization", defined as the average of these three items. "Organization" deals with three issues related to the form and function of planning organizations (e.g. Andersen and Jonsson, 2006, Pinjala et al., 2006). The internal consistency, or degree of correlation among the three items for the same construct, within this new variable was tested using Cronbach's alpha. The corresponding alpha value was 0.73 , which is higher than the 0.70 value normally mentioned as the lowest acceptable alpha level (Hair et al., 1998) for a reliable variable (scale). When conducting factor analysis, all three individual items within the tested variable (scale) had factor loadings that exceeded 0.7 on a single factor. This indicates that the new variable (scale) is homogeneous and does not measure multiple constructs. A new variable (scale) was also formed for the items "Inventory account accuracy" and "Lead-time precision", which in one analysis is exchanged for "Basic data", a variable defined as the average of those two items. The new variable contains two central basic data variables used in materials planning (Hamilton, 2003). 
Full reference: Jonsson, P. (2008). Exploring problems related to the materials planning user environment. International Journal of Production Economics. 113(1): 383-400.

In evaluating the use of planning methods, respondents were given four alternatives: (1) the method is not used, (2) the method is used as a complement, (3) the method is used as a main method, (4) don't know. Respondents marking alternatives 2 or 3 were coded as users. "Main method" was defined as the method used for the majority of items.

Two operational re-order point and five operational MRP strategies were included in the analysis. The seven operational materials planning strategies and their related measures are defined in Table 2. Measures coded with "2" represent analytically defined variables, frequently revised (more frequently than annually) variables and high (at least daily) planning frequencies. In accordance with Jonsson and Mattsson (2007), these are considered to have positive performance impact, and measures coded with " 1 " to have negative impact.

Table 2. Materials planning strategy measures

\begin{tabular}{|l|l|l|}
\hline Method & Planning strategy & Measure \\
\hline $\begin{array}{l}\text { Re-order } \\
\text { point } \\
\text { Re-order } \\
\text { point } \\
\text { MRP }\end{array}$ & $\begin{array}{l}\text { 1. Analytical order point } \\
\text { 2. Frequency of order point } \\
\text { revision } \\
\text { 3. Analytical lead-time } \\
\text { determination }\end{array}$ & $\begin{array}{l}\text { 1) Based on experience and judgment, 2) Calculated as } \\
\text { lead-time demand plus safety stock } \\
\text { 1) Annually or less frequent, 2) At least a couple of times } \\
\text { per year } \\
\text { 1) Based on general judgment and experience, 2) Based on } \\
\text { calculations in the ERP system or on monitored actual } \\
\text { lead-times } \\
\text { 1) Annually or less frequent, 2) At least a couple of times } \\
\text { MRP }\end{array}$ \\
$\begin{array}{l}\text { 4. Frequency of safety stock } \\
\text { revision }\end{array}$ & $\begin{array}{l}\text { 5. Frequency of } \\
\text { manufacturing lead-time } \\
\text { revision } \\
\text { 6. Frequency of purchasing } \\
\text { lead-time revision } \\
\text { 7. Planning frequency }\end{array}$ & $\begin{array}{l}\text { 1) Annually or less frequent, 2) Reviews a couple of times } \\
\text { a year or more frequent }\end{array}$ \\
MRP & $\begin{array}{l}\text { 1) Annually or less frequent, 2) Reviews a couple of times } \\
\text { a year or more frequent } \\
\text { 1) Once a week or less frequent; 2) Daily or more frequent }\end{array}$ \\
\hline
\end{tabular}

The planning environment can be described by product related, demand (material-flow) related and process related variables (Krajewski et al., 1987, Berry and Hill, 1992, Jonsson and Mattsson, 2003). Here, product structure complexity and degree of value added at order entry describe the product characteristics. Customer order volume/frequency describes the demand characteristics. Shop floor layout, batch-size and through-put time describe the material supply/manufacturing process characteristics. The same definitions of the six planning environment variables as in Jonsson and Mattsson (2003) were used. Focus was on the "difficult" planning environment alternatives, defined in the following ways:

1. Product structure complexity - Three or more levels in the bill-of-materials

2. Degree of value added at order entry - Assemble-to-order, manufacture-to-order, engineer-to-order in manufacturing operations and postponement strategies in distribution and spare part operations (NOT make-to-stock and deliver from stock) 
Full reference: Jonsson, P. (2008). Exploring problems related to the materials planning user environment. International Journal of Production Economics. 113(1): 383-400.

3. Customer order volume/frequency - Few large customer orders per year (NOT large number of customer orders with medium quantities per year or frequent calloffs and delivery schedules)

4. Shop floor layout - Functional layout (NOT cellular or continuous line layout)

5. Batch sizes - Manufacturing or purchasing batch sizes equivalent to or larger than a few weeks of demand

6. Through-put time - Through-put times in manufacturing or lead times from suppliers of at least a few weeks.

Variables one (product structure complexity) and four (shop floor layout) are only relevant for manufacturing companies, while the other four variables are relevant and measured for manufacturing and distributing companies.

Two variables and questions were used to measure the perceived materials planning performance: (1) user friendliness ("How easy is the method to understand and use? How time-consuming is it?") and (2) operational performance ("How well does the control of inventories and material flows match your expectations, in terms of achieving low tied-up capital, high customer service and few shortages?”). Each question related to the respective variable includes multiple questions. The respondents were asked to weight the different sub-questions equally when answering. The answers were measured on sevenpoint scales, where "1" represented "poor"/“not at all”, “4” satisfactory, and "7” "very well”. Previous studies have used the perceived overall performance of manufacturing (Safizadeh et al., 1996), the inventory turnover rate (Rabinovich et al., 2003) and inventory days on hand in different inventories (Safizadeh and Ritzman, 1997) as measures for materials management performance. To validate our two measures of perceived planning performance, we have included two measures that are in line with those tested and used in previous studies. The first is about the perceived overall inventory turnover rate in relation to the competitors in the industry (measured on a seven-point scale ranging from much lower to much higher) and the second about the perceived overall delivery service performance to customer in relation to the competitors in the industry (measured on a seven-point scale ranging from much worse to much better). These validity tests are explained in the next section.

\subsection{Reliability and Validity}

To increase the reliability and validity of the questionnaire, it was pre-tested and a number of questions were adjusted before finally sending it out. Most respondents were PLAN members. This should ensure familiarity with planning methods.

The industry and size of the respondents closely matched the demographics of Swedish manufacturing firms in general (Olhager and Seldin, 2004). To increase the response rate and to identify the reasons for non-responses, potential respondents received a reminder by phone. Addressees were also requested to reply even if they did not intend to complete the questionnaire. Four main reasons were given for not answering the questionnaire, with a total of 111 non-responses. Fifty-four (49\%) stated that their company had no production or inventories and was therefore not relevant for the study; 27 (24\%) did not have sufficient knowledge to answer accurately; 23 (21\%) did not have enough time or did not wish to answer the questionnaire; and 7 (6\%) no longer worked for the company. 
Full reference: Jonsson, P. (2008). Exploring problems related to the materials planning user environment. International Journal of Production Economics. 113(1): 383-400.

The population of manufacturing companies could thus be adjusted by the fifty-four irrelevant companies without production, down to 519, which gives an adjusted response rate of $29 \%$. If $49 \%$ of all companies were irrelevant for the study, then the response rate would be $55 \%$. The responding adjusted distribution company population is 455 and the adjusted response rates $12 \%$ and $22 \%$ respectively. Chi-square tests did not reveal any significant difference between respondents and non-respondents regarding company size or industry in any of the surveys. Non-response bias should therefore not be a problem and it should be possible to generalize the findings for most manufacturing and distribution industries.

A four-page file with definitions and descriptions of the methods for materials planning was attached to the surveys. The aim was to ensure that the measures were valid and that the respondents had the same definitions of planning methods, which further improved the understanding and validity of the study.

The reliability of the scale made up of multiple items was discussed in the previous section. The criterion-related (predictive) validity of the subjective measure of perceived performance was tested by assessing the relationship between scores on the predictor scale and measures of the perceived overall inventory turnover rate, in comparison to the competitors in the industry (measured on a 7-point scale ranging from much lower to much higher), and the perceived overall delivery service performance to customer in relation to the competitors in the industry (measured on a 7-point scale ranging from much worse to much better). Table 3 shows the bivariate correlations between the measures.

For MRP there are significant correlations between the perceived operational performance and both the inventory turnover rate and delivery service. The correlation between the perceived user friendliness and the delivery service is also significant. For the re-order point method, there are significant correlations between both the perceived operational performance and user friendliness and the inventory turnover rate. However, the correlations with the delivery service are not significant. The correlations with the inventory turnover rate are expected to be higher than with the delivery service, because the method directly affects the inventory levels but only indirectly the delivery service. For the fixed-order interval, run-out time planning and kanban methods, the only significant correlation existed between the operational performance and delivery service for kanban. The levels of significance are lower for these methods, mainly because of the lower number of respondents. The correlations between the perceived operational performance and perceived user friendliness are significant $(\mathrm{p}<0.01)$ for all methods. This is in line with the expectations that the user friendliness is positively affected by the operational performance. The correlation coefficient for the correlation between the two overall measures (inventory turnover rate and delivery service) was 0.154 , which was significant on the $\mathrm{p}<0.05$ level. These tests validate the appropriateness of using the perceived operational performance as a performance measure, especially for the MRP and re-order point methods. 
Full reference: Jonsson, P. (2008). Exploring problems related to the materials planning user environment. International Journal of Production Economics. 113(1): 383-400.

Table 3. Correlation between perceived planning performance and ITR/delivery service

\begin{tabular}{|l|c|c|}
\hline Perceived performance & \multicolumn{2}{|c|}{ Objective performance } \\
\cline { 2 - 3 } & $\begin{array}{c}\text { Inventory } \\
\text { turnover rate } \\
\text { (ITR) }\end{array}$ & Delivery service \\
\hline User friendliness (Re-order point) & $0.203^{*}$ & -0.040 \\
\hline User friendliness (Fixed-order interval) & -0.061 & 0.246 \\
\hline User friendliness (Run-out time planning) & 0.060 & 0.080 \\
\hline User friendliness (Kanban) & -0.086 & 0.154 \\
\hline User friendliness (MRP) & 0.125 & $0.181^{*}$ \\
\hline Operational performance (Re-order point) & $0.196^{*}$ & 0.020 \\
\hline Operational performance (Fixed-order interval) & 0.228 & -0.001 \\
\hline Operational performance (Run-out time planning) & 0.169 & 0.169 \\
\hline Operational performance (Kanban) & 0.073 & $0.242^{*}$ \\
\hline Operational performance (MRP) & $0.324^{* *}$ & $0.262^{* *}$ \\
\hline
\end{tabular}

Note: Pearson correlation, *Significant $(\mathrm{p}<0.05)$; **Significant $(\mathrm{p}<0.01)$.

\section{Findings}

The analysis presented in this section is conducted and presented in five steps: (1) developing an empirical taxonomy of user environments, (2) comparing company sizes and difficult planning environment characteristics between user environment cluster groups, (3) describing what materials planning methods are used and how they are used in different user environments, (4) describing the perceived planning performance of materials planning methods in various user environments, and (5) explaining the characteristics of user environments among companies with high and low perceived planning performance, respectively.

\subsection{Identifying a user-environment taxonomy}

Cluster analysis was employed to identify distinct user-environment types from the variables "Software support”, "Education and knowledge”, "Organization” and "Basic data”. Ward's minimum variance cluster method was used to identify outliers and form appropriate numbers of clusters. There are several rules of thumb when finding an appropriate number of clusters. One of the most appropriate rules is to focus on the pronounced increase in the tightness of the clusters. Small changes of the clustering (agglomeration) coefficient when conducting hierarchical cluster analysis indicate that fairly homogeneous clusters are being merged, while joining two very different clusters results in a large percentage change in the coefficient (Hair et al., 1998). For our data, changes between two, three, four and five clusters resulted in 6 to 15\% changes in the coefficient. No change was considered significantly larger than the others.

When moving from the three- to the four-cluster solution, two of the clusters were more or less unchanged. The third cluster was split into two new clusters. All clusters in the four-cluster solution are distinct from each other and easy to interpret as different and homogeneous clusters. Therefore, the four-cluster model was chosen. Non-hierarchical cluster analysis with seed points from the hierarchical results were used to fine-tune the results and present the final clusters. To check the stability of the cluster solution, a 
Full reference: Jonsson, P. (2008). Exploring problems related to the materials planning user environment. International Journal of Production Economics. 113(1): 383-400.

second non-hierarchical analysis was performed, this time allowing the procedure to collect seed points at random. The cluster sizes were comparable and the final cluster solution is therefore considered consistent.

The clustering variables were compared by group means using one-way ANOVA tests. Scheffe's pairwise comparison test was used to identify significant differences between individual pairs of groups on each of the four individual variables. Both tests showed significant differences between the groups, indicating that the groups were distinct from each other (Table 4).

Table 4. Clusters and clustering variables

\begin{tabular}{|c|c|c|c|c|c|}
\hline \multirow[t]{2}{*}{ Variables } & \multicolumn{4}{|c|}{$\begin{array}{l}\text { Clusters } \\
\end{array}$} & \multirow[t]{2}{*}{ F-statistics } \\
\hline & $\begin{array}{l}\text { 1. Leaders } \\
(\mathbf{n}=76) \\
\text { Mean (SD) }\end{array}$ & $\begin{array}{c}\begin{array}{l}\text { 2. Software } \\
\text { reliers }(n=55)\end{array} \\
\text { Mean (SD) }\end{array}$ & $\begin{array}{l}\text { 3. Organizers } \\
(\mathbf{n = 2 9 )} \\
\text { Mean (SD) }\end{array}$ & $\begin{array}{l}\text { 4. Laggers } \\
(\mathbf{n}=20) \\
\text { Mean (SD) }\end{array}$ & \\
\hline Software support & $\begin{array}{c}5.71(0.91) \\
{[2,3,4]}\end{array}$ & $\begin{array}{c}5.02(1.14) \\
{[1,3,4]}\end{array}$ & $\begin{array}{c}2.03(0.63) \\
{[1,2]}\end{array}$ & $\begin{array}{c}2.15(0.99) \\
{[1,2]}\end{array}$ & $159.21^{* *}$ \\
\hline $\begin{array}{l}\text { Education \& } \\
\text { knowledge }\end{array}$ & $\begin{array}{c}5.46(0.79) \\
{[2,3,4]}\end{array}$ & $\begin{array}{c}3.04(1.33) \\
{[1,4]}\end{array}$ & $\begin{array}{c}3.31(1.36) \\
{[1,4]}\end{array}$ & $\begin{array}{c}2.15(0.93) \\
{[1]}\end{array}$ & $81.92 * *$ \\
\hline Organization & $\begin{array}{c}5.42(0.96) \\
{[2,3,4]}\end{array}$ & $\begin{array}{c}3.20(1.00) \\
{[1,3]}\end{array}$ & $\begin{array}{c}4.34(0.85) \\
{[1,2,4]}\end{array}$ & $\begin{array}{c}3.18(1.11) \\
{[1,3]}\end{array}$ & $77.26 * *$ \\
\hline Basic data & $\begin{array}{c}5.11(1.28) \\
{[2,4]}\end{array}$ & $\begin{array}{c}3.70(1.07) \\
{[1,3,4]}\end{array}$ & $\begin{array}{c}5.22(1.20) \\
{[2,4]}\end{array}$ & $\begin{array}{c}2.00(0.84) \\
{[1,2,3]}\end{array}$ & $49.10 * *$ \\
\hline
\end{tabular}

Note: F-statistics are derived from one-way ANOVA. ** indicates significantly different variable on the $\mathrm{p}<0.01$ level. Numbers in brackets [ ] indicate the group numbers with which this group is significantly different at the $\mathrm{p}<0.05$ level. Scheffe's pairwise test of means was used for identifying pairwise differences.

\subsection{Company size, type of operation and planning environment characteristics}

The analyses in Sections 4.2 and 4.3 check for bias caused of the materials planning usage and control variables (company size, type of operation, planning environment characteristics, and operational strategies of materials planning methods). Here, the differences of company size, type of operation and difficult planning environment are compared between user environment cluster groups.

No significant difference in company size was identified between companies in the four clusters (Table 5). Consequently, the company size should not explain any difference identified between clusters in the further analysis.

Table 5. Average company size by cluster groups

\begin{tabular}{|l|c|c|c|c|c|}
\hline Variables & \multicolumn{4}{|c|}{ Clusters } & Chi-square \\
\cline { 2 - 6 } & $\begin{array}{c}\text { 1. Leaders } \\
(\mathbf{n = 7 6 )}\end{array}$ & $\begin{array}{c}\text { 2. Software } \\
\text { reliers (n=55) }\end{array}$ & $\begin{array}{c}\text { 3. Organizers } \\
(\mathbf{n = 2 9 )}\end{array}$ & $\begin{array}{c}\text { 4. Laggers } \\
(\mathbf{n = 2 0 )}\end{array}$ & \\
& Mean rank & Mean rank & Mean rank & Mean rank & \\
\hline Size turnover & 87.3 & 83.0 & 88.2 & 88.6 & 0.35 \\
\hline Size employees & 84.2 & 90.2 & 92.5 & 104.7 & 0.95 \\
\hline
\end{tabular}

Note: Kruskal Wallis test could not reveal any significant difference between cluster groups. Sizes measured on 3-point scales (Turnover: $<10$ Million $€ / 10-30$ Million $€ />30$ Million $€$, Employees: $<50 / 50$ $300 />300$ ) 
Full reference: Jonsson, P. (2008). Exploring problems related to the materials planning user environment. International Journal of Production Economics. 113(1): 383-400.

Still, some differences in user environments could be identified between companies of various sizes. Table 6 compares the user environments among small and large companies (as defined in Table 1). All user-environment issues have lower means among the large companies. However, the perceived importance of the software support is the only issue that differs significantly on the $\mathrm{p}<0.05$ level between company sizes. The inventory account accuracy and lead-time precision differ on the $\mathrm{p}<0.07$ levels. Large companies use MRP as main method to a significantly larger extent compared with small companies (75 and 62\%, respectively, among the two groups of company sizes), and the re-order point as main method to a significantly lesser extent (26 and 47\%, respectively, among the two groups of company sizes). The different method usage may explain some of the user-environment differences; in particular, the importance of software support and basic data quality could be considered more critical in MRP than in re-order point environments. These issues may not be so important in small companies due to the lower use of MRP. Previous studies identified education and knowledge as more critical in large firms when implementing ERP systems (Sum et al., 1999). Here, no significant difference was identified in perceived problems related to education and knowledge between small and large companies.

Table 6. User environment among large and small sized companies

\begin{tabular}{|c|c|c|c|}
\hline & $\begin{array}{c}\text { Small } \\
\text { Mean (SD) }\end{array}$ & $\begin{array}{c}\text { Large } \\
\text { Mean (SD) }\end{array}$ & F-statistics \\
\hline Software support & $4.81(1.69)$ & $4.13(1.80)$ & $6.91 * *$ \\
\hline Education and knowledge & $4.15(1.75)$ & $3.88(1.56)$ & 1.19 \\
\hline Management commitment & $4.43(1.62)$ & $4.29(1.82)$ & 0.30 \\
\hline Organizational design & $4.55(1.72)$ & $4.53(1.60)$ & 0.01 \\
\hline Available planning time & $4.12(1.82)$ & $3.99(1.56)$ & 0.26 \\
\hline Inventory account accuracy & $4.95(1.64)$ & $4.44(2.08)$ & 3.46 \\
\hline Lead-time precision & $4.31(1.64)$ & $3.83(1.90)$ & 3.47 \\
\hline
\end{tabular}

Note: ${ }^{* *}$ significant $\mathrm{p}<0.01$ and $*$ significant $\mathrm{p}<0.05$ (t tests).

The respondents were asked to relate their answers to materials planning in one of three alternative types of operations: manufacturing, distribution, or spare-part operations. The cluster groups were compared between the different types of operations (Table 7).

Groups 2 and 4 were represented by significantly $(\mathrm{p}<0.05)$ more companies controlling manufacturing operations compared to what was expected (assuming evenly distributed types of operations between cluster groups). Group 3 had significantly $(\mathrm{p}<0.05)$ more companies controlling distribution and spare-part operations than was expected. 
Full reference: Jonsson, $P$. (2008). Exploring problems related to the materials planning user environment. International Journal of Production Economics. 113(1): 383-400.

Table 7. Type of operation by cluster groups

\begin{tabular}{|l|c|c|c|c|}
\hline \multirow{2}{*}{\begin{tabular}{l} 
Variables (Type of \\
\cline { 2 - 5 }
\end{tabular}} & $\begin{array}{c}\text { 1. Leaders } \\
(\mathbf{n}=\mathbf{7 6})\end{array}$ & $\begin{array}{c}\text { 2. Software } \\
\text { reliers (n=55) }\end{array}$ & $\begin{array}{c}\text { 3. Organizers } \\
(\mathbf{n = 2 9 )}\end{array}$ & $\begin{array}{c}\text { 4. Laggers } \\
(\mathbf{n = 2 0})\end{array}$ \\
& Number (\%) & Number (\%) & Number (\%) & Number (\%) \\
\hline Manufacturing & $57(75 \%)$ & $47(87 \%)$ & $16(55 \%)$ & $17(85 \%)$ \\
\hline Distribution & $16(21 \%)$ & $5(9 \%)$ & $11(38 \%)$ & $2(10 \%)$ \\
\hline Spare part & $3(4 \%)$ & $2(4 \%)$ & $2(7 \%)$ & $1(5 \%)$ \\
\hline & $76(100 \%)$ & $55(100 \%)$ & $29(100 \%)$ & $20(100 \%)$ \\
\hline
\end{tabular}

Note: Chi-square tests of the $4 \times 2$ matrix conducted after merging distribution and spare parts into one variable could reveal significant difference between actual and expected counts (Chi-square $=11.58$, $\mathrm{p}<0.01)$.

Based on the characteristics described in Tables 4, 5 and 8, the four identified userenvironment clusters were named "Leaders", "Software reliers", "Organizers" and "Laggers". Brief interpretations of the meanings of the groups are given below.

Cluster 1 - Leaders: The first cluster is the largest cluster and contains about $40 \%$ of the surveyed companies $(n=76)$. It was named "Leaders" because it showed significantly higher means on three of the four clustering variables than did the three other groups. For the fourth variable, basic data, it was significantly higher compared to two of the groups but not compared to group 3 (“Organizers"). The leaders, consequently, consider the software support in the ERP system, the education and knowledge for materials planning issues, the management commitment to materials planning, the way materials planning is organized, the available time for materials planning, the inventory account accuracy, and the lead-time precision in the basic data files to be good enough to make the materials planning methods work properly. The available time, inventory account accuracy, and lead-time precision are the variables they are least happy with, but still all averages are above " 5 " on the 7-point scale.

Cluster 2 - Software reliers: This is the second largest group $(n=55)$. It showed low means on all variables except for software support. For organizational design and available planning time, it had the lowest mean among all groups, although not significantly lower than group 4 ("Laggers"). Because software support was the only issue not considered very problematic in order to make the materials planning methods work properly, it was named "Software reliers". The second highest mean exists for the inventory account accuracy, but it is still significantly lower than in two of the other groups. This group is represented by a significantly larger proportion of answers related to manufacturing operations, and lower proportion related to distribution and spare-part operations, compared to the average.

Cluster 3 - Organizers: This third group $(n=29)$ has the opposite characteristics compared to the Software reliers. The way the materials planning is organized and the available time for materials planning are considered significantly less problematic than in group 2 ("Software reliers") and group 4 ("Laggers"). Also the basic data issues (the inventory account accuracy and lead-time precision) have significantly higher means compared to groups 2 and 4 . The inventory account accuracy mean is even higher than in group 1 ("Leaders"). The software support, available in the ERP system, is the issue that is 
Full reference: Jonsson, P. (2008). Exploring problems related to the materials planning user environment. International Journal of Production Economics. 113(1): 383-400.

considered most problematic in order to make the materials planning methods work properly. The mean is as low as 2.03 on the 7 -point scale. The group is represented by a significantly larger proportion of answers related to distribution and spare-part operations, and a lower proportion related to manufacturing operations, compared to the average.

Cluster 4 - Laggers: The last group, also the smallest $(n=20)$, showed low means on all clustering variables; consequently all issues are considered problematic in order for the materials planning methods to work properly. Especially the software support, education and knowledge, inventory account accuracy, and lead-time precision were considered too low in order to make the materials planning methods work properly. The means of these issues were significantly lower than in all other groups (except for software support, which was lower in the "Organizers" group).

Goups 1 and 4 represent the extremes, those who consider all user-environment issues to be either appropriate or inappropriate. Group 2 is a quite large group of companies mainly relying on the software support in the ERP system, but which do not have sufficient education, knowledge, training, organization or basic data, when controlling manufacturing operations. It consequently has characteristics similar to those identified in unsuccessful ERP implementations (e.g. Sum et al., 1999; Petroni, 2002). Group 3 is also interesting, because it represents companies in a quite different user environment than does group 2. There are more distribution and spare-part operations in this group compared to the other groups. The focus is on the way the materials planning is organized, not allowing each planner to take care of too many items, and making sure that the inventory account balance and lead-time precision in the basic data files are accurate. The software support in the ERP system is, however, considered problematic.

In table 8, the six variables describing planning environment characteristics are compared between the four cluster groups. The degree of value added at order entry is the only characteristic that is significantly different between the groups. The Leaders and Organizers have the simplest environments, with significantly more companies making to stock and delivering customer orders directly from finished goods stocks, compared to the Software reliers and Laggers. Software reliers and Laggers use assemble-to-order, make-to-order and engineer-to-order in manufacturing operations and postponement strategies in distributing and spare part operations, to significantly larger extent than the two other cluster groups. In such environments, re-order point methods are normally less appropriate (e.g. Jonsson and Mattsson, 2003). The difference in degree of value added at order entry between the cluster groups may affect the perceived planning performance of the respective group. The overall bias created by the planning environment should, however, be low, since five of six planning environment variables did not differ significantly between cluster groups. 
Full reference: Jonsson, $P$. (2008). Exploring problems related to the materials planning user environment. International Journal of Production Economics. 113(1): 383-400.

Table 8. Difficult planning environment by cluster groups

\begin{tabular}{|c|c|c|c|c|c|}
\hline & \multicolumn{4}{|c|}{ Clusters } & \multirow[t]{2}{*}{ Chi-square } \\
\hline & $\begin{array}{c}\text { 1. Leaders } \\
(\mathbf{n}=76) \\
\text { Number }(\%)\end{array}$ & $\begin{array}{c}\begin{array}{c}\text { 2. Software } \\
\text { reliers }(n=55) \\
\text { Number }(\%)\end{array} \\
\end{array}$ & $\begin{array}{l}\begin{array}{l}\text { 3. Organizers } \\
(\mathbf{n}=29)\end{array} \\
\text { Number }(\%)\end{array}$ & $\begin{array}{l}\text { 4. Laggers } \\
(\mathbf{n}=20) \\
\text { Number (\%) }\end{array}$ & \\
\hline $\begin{array}{l}\text { More than two } \\
\text { levels in the BOM }\end{array}$ & $33(54 \%)$ & $33(62 \%)$ & $11(50 \%)$ & $13(68 \%)$ & 1.55 \\
\hline MTO/ATO/ETO & $40(53 \%)$ & $45(82 \%)$ & $16(57 \%)$ & $16(80 \%)$ & $14.2 * *$ \\
\hline Few/large orders & $15(20 \%)$ & $8(15 \%)$ & $5(18 \%)$ & $5(25 \%)$ & 1.22 \\
\hline Functional layout & $43(70 \%)$ & $36(69 \%)$ & $15(79 \%)$ & $10(53 \%)$ & 3.32 \\
\hline Large batch sizes & $25(33 \%)$ & $22(40 \%)$ & $15(54 \%)$ & $8(40 \%)$ & 3.52 \\
\hline $\begin{array}{l}\text { Long through-put } \\
\text { times }\end{array}$ & $40(53 \%)$ & $35(64 \%)$ & 17 (63\%) & $16(80 \%)$ & 5.45 \\
\hline
\end{tabular}

Note: The counts represent the number of respondents answering alternative coded as being a "difficult planning environment”, see Section 3.2. The percentages are calculated as the counts divided by number of cluster group members. Figures in bold are significantly different from the expected figures, if environment types were evenly distributed between cluster groups.

\subsection{Materials planning application}

Materials planning applications are compared between the cluster groups in terms of (1) materials planning method used as "main method" and (2) operational materials planning strategy applied when designing and using the two most commonly applied methods (reorder point and MRP method). By main method is meant the method used to control the majority of items. No materials planning method was significantly more used as main method in any cluster group (Table 9). This is expected, because the analysis in Section 4.2 showed that the planning environment was very similar in the different cluster groups.

Table 9. MPC main methods by cluster groups

\begin{tabular}{|l|c|c|c|c|l|}
\hline \multirow{2}{*}{ Variables } & \multicolumn{4}{|c|}{ Clusters } & \multirow{2}{*}{ Chi-square } \\
\cline { 2 - 5 } & $\begin{array}{c}\text { 1. Leaders } \\
(\mathbf{n}=\mathbf{7 6})\end{array}$ & $\begin{array}{c}\text { 2. Software } \\
\text { reliers (n=55) }\end{array}$ & $\begin{array}{c}\text { 3. Organizers } \\
(\mathbf{n = 2 9 )}\end{array}$ & $\begin{array}{c}\text { 4. Laggers } \\
(\mathbf{n = 2 0})\end{array}$ & \\
& Number (\%) & Number (\%) & Number (\%) & Number (\%) & \\
\hline Re-order point & $30(39 \%)$ & $23(42 \%)$ & $14(48 \%)$ & $9(45 \%)$ & 0.38 \\
\hline Periodic review & $8(11 \%)$ & $4(7 \%)$ & $2(7 \%)$ & $3(15 \%)$ & NA \\
\hline Run-out time & $14(18 \%)$ & $4(7 \%)$ & $6(21 \%)$ & $3(15 \%)$ & NA \\
\hline MRP & $50(66 \%)$ & $39(71 \%)$ & $18(62 \%)$ & $15(75 \%)$ & 0.42 \\
\hline Kanban & $9(12 \%)$ & $4(7 \%)$ & $4(14 \%)$ & $3(15 \%)$ & NA \\
\hline
\end{tabular}

Note: More than one main method could be chosen. The percentages are calculated as the counts divided by number of cluster group members. Chi-square tests not applicable for the periodic review, run-out time and kanban methods because of too few counts $(<5)$ in cells.

When comparing the materials planning strategies for designing and using the materials planning methods, two strategies were studied for the re-order point and five for the MRP method; see Table 2 . 
Full reference: Jonsson, P. (2008). Exploring problems related to the materials planning user environment. International Journal of Production Economics. 113(1): 383-400.

Some significantly different materials planning strategies were identified between the cluster groups (Table 10). The "Software reliers" reviewed the re-order point in the reorder point system significantly less frequently than the other groups. The same pattern is true for the MRP planning strategies, where the "Software reliers" review the safety stock significantly less frequently than the other groups. Noticeable is that the review frequencies among the "Software reliers" are even significantly lower than those of the "Laggers". The "Leaders", on the other hand, show higher figures for almost all strategies than do the other groups. However, only the frequency of revising purchasing lead-times is significantly higher compared to the other groups. It consequently seems that the "Software reliers" work less actively with determining and reviewing planning parameters, compared to the other groups - something that could have direct effects on the planning performances. This behavior is not surprising, because several of the review activities are done manually, and the interpretation is that this group relies heavily on the ERP system when it comes to materials planning.

Table 10. Operational materials planning strategy by cluster groups

\begin{tabular}{|c|c|c|c|c|c|}
\hline \multirow{2}{*}{$\begin{array}{l}\text { Re-order point } \\
\text { (ROP) and MRP } \\
\text { strategies }\end{array}$} & \multicolumn{4}{|c|}{ Clusters } & \multirow[t]{2}{*}{ Chi-square } \\
\hline & $\begin{array}{c}\text { 1. Leaders } \\
(\mathbf{n}=76) \\
\text { Number }(\%)\end{array}$ & $\begin{array}{l}\begin{array}{c}2 . \text { Software } \\
\text { reliers }(n=55)\end{array} \\
\text { Number (\%) }\end{array}$ & $\begin{array}{l}\begin{array}{c}\text { 3. Organizers } \\
(\mathbf{n}=29)\end{array} \\
\text { Number (\%) }\end{array}$ & $\begin{array}{l}\begin{array}{l}\text { 4. Laggers } \\
(\mathbf{n}=20)\end{array} \\
\text { Number (\%) }\end{array}$ & \\
\hline $\begin{array}{l}\text { Analytical } \\
\text { determination of re- } \\
\text { order point (ROP) }\end{array}$ & 39 (75\%) & 22 (51\%) & $16(64 \%)$ & $8(57 \%)$ & 6.17 \\
\hline $\begin{array}{l}\text { Frequent revision of } \\
\text { re-order point (ROP) }\end{array}$ & 32 (56\%) & $12(27 \%)$ & $14(58 \%)$ & $6(40 \%)$ & $10.82^{*}$ \\
\hline $\begin{array}{l}\text { Analytical } \\
\text { determination of } \\
\text { manufacturing lead- } \\
\text { time (MRP) }\end{array}$ & $38(72 \%)$ & $31(70 \%)$ & $12(67 \%)$ & $8(53 \%)$ & 2.85 \\
\hline $\begin{array}{l}\text { Frequent revision of } \\
\text { manufacturing lead- } \\
\text { time (MRP) }\end{array}$ & $22(42 \%)$ & $12(27 \%)$ & $4(21 \%)$ & $5(33 \%)$ & 3.91 \\
\hline $\begin{array}{l}\text { Frequent revision of } \\
\text { purchasing lead-time } \\
\text { (MRP) }\end{array}$ & $30(58 \%)$ & $14(31 \%)$ & $5(26 \%)$ & $3(20 \%)$ & $12.27^{* *}$ \\
\hline $\begin{array}{l}\text { Frequent revision of } \\
\text { safety stock (MRP) }\end{array}$ & $31(62 \%)$ & $14(33 \%)$ & $11(58 \%)$ & $8(53 \%)$ & $8.65^{*}$ \\
\hline $\begin{array}{l}\text { High planning } \\
\text { frequency (MRP) }\end{array}$ & $38(74 \%)$ & 35 (76\%) & $16(80 \%)$ & $9(56 \%)$ & 3.07 \\
\hline
\end{tabular}

Note: The counts represent the number of respondents answering alternative " 2 " in Table 8 . The percentages are calculated as the counts divided by number of cluster group members. Figures in bold are significantly different from the expected figures, if strategies were evenly distributed between cluster groups.

\subsection{Perceived materials planning performance}

The perceived planning performances among companies in different user environments were analyzed in two ways. Firstly, the performance measures "perceived user friendliness", "perceived operational planning performance", "relative inventory turnover 
Full reference: Jonsson, P. (2008). Exploring problems related to the materials planning user environment. International Journal of Production Economics. 113(1): 383-400.

rate" and "relative delivery service" were compared between the four cluster groups. Secondly, the user environments were compared between companies with low and high perceived user friendliness and low and high perceived operational performance, respectively.

Perceived planning performance in cluster groups

Table 11 shows the perceived user friendliness of the five studied materials planning methods in the four cluster groups. The "Software reliers" and "Laggers" are the cluster groups with lowest overall perceived user friendliness. For MRP it is significantly lower compared to the "Leaders" group. This can be explained by the fact that these two groups have less focus on the organizational and basic data issues than do the two other groups, which should be important issues for achieving high user friendliness. The "Software reliers" group also worked less actively with up-dating planning parameters than did the other groups (Table 2), something that also may impact the perceived user friendliness.

Table 11. Perceived MPC user friendliness by cluster groups

\begin{tabular}{|c|c|c|c|c|c|}
\hline \multirow{3}{*}{ Variables } & \multicolumn{4}{|c|}{$\begin{aligned} \text { Clusters } \\
\end{aligned}$} & \multirow{3}{*}{ F-statistics } \\
\hline & $\begin{array}{l}\text { 1. Leaders } \\
(\mathrm{n}=72)\end{array}$ & $\begin{array}{l}\text { 2. Software } \\
\text { reliers }(n=43)\end{array}$ & $\begin{array}{l}\text { 3. Organizers } \\
(n=28)\end{array}$ & $\begin{array}{l}\text { 4. Laggers } \\
(n=35)\end{array}$ & \\
\hline & Mean (SD) & Mean (SD) & Mean (SD) & Mean (SD) & \\
\hline Re-order point & $4.89(1.12)$ & $4.28(1.10)$ & $4.42(1.38)$ & $4.07(1.38)$ & $3.52 *$ \\
\hline Periodic review & $4.29(1.27)$ & $3.70(1.16)$ & $4.67(1.97)$ & $3.00(0.71)$ & 1.85 \\
\hline Run-out time & $4.75(1.45)$ & $4.33(1.29)$ & $4.89(0.93)$ & $4.13(1.13)$ & 0.81 \\
\hline MRP & $\begin{array}{c}.88(0.98) \\
{[2,4]}\end{array}$ & $\begin{array}{c}4.14(1.37) \\
{[1]}\end{array}$ & $4.52(1.36)$ & $\begin{array}{c}3.83(1.10) \\
{[1]}\end{array}$ & $5.09 * *$ \\
\hline Kanban & $5.56(1.16)$ & $4.91(1.31)$ & $4.75(2.38)$ & $4.33(1.78)$ & 2.13 \\
\hline
\end{tabular}

Note: F-statistics are derived from one-way ANOVA. ** indicates significantly different variable on the $\mathrm{p}<0.01$ level. Numbers in brackets [ ] indicate the group numbers with which this group is significantly different at the $\mathrm{p}<0.05$ level. Scheffe's pairwise test of means was used for identifying pairwise differences.

Similar findings were obtained when comparing the perceived operational planning performances between cluster groups (Table 12). The "Software reliers" group shows the lowest perceived operational performance among re-order point users, significantly lower than the "Leaders" group. For MRP, the perceived performance is significantly higher among "Leaders" compared to both "Software reliers" and "Laggers". It is a bit surprising that the perceived MRP performance is not lower among the "Organizers", because this is the group that finds the software support most problematic in order to make the materials planning methods work properly; however, its performance is only slightly better than that of the "Software reliers". The low perceived performance among the "Software reliers" may to some extent be explained by their lack of frequent reviewing of planning parameters. Some of the perceived performance differences between cluster groups could also be explained by the difference in planning environment, discussed in Section 4.2. 
Full reference: Jonsson, P. (2008). Exploring problems related to the materials planning user environment. International Journal of Production Economics. 113(1): 383-400.

Table 12. Perceived operational MPC performance by cluster groups

\begin{tabular}{|c|c|c|c|c|c|}
\hline \multirow[t]{3}{*}{ Variables } & \multicolumn{4}{|c|}{$\begin{aligned} \text { Clusters } \\
\end{aligned}$} & \multirow{4}{*}{ F-statistics } \\
\hline & \multirow{3}{*}{$\begin{array}{l}\text { 1. Leaders } \\
(\mathbf{n}=72) \\
\text { Mean (SD) }\end{array}$} & \multirow{3}{*}{$\begin{array}{l}\text { 2. Software } \\
\text { reliers }(n=43) \\
\text { Mean }(S D)\end{array}$} & \multirow{3}{*}{$\begin{array}{l}\text { 3. Organizers } \\
\quad(\mathbf{n}=\mathbf{2 8}) \\
\text { Mean (SD) }\end{array}$} & \multirow{3}{*}{$\begin{array}{l}\text { 4. Laggers } \\
(n=35) \\
\text { Mean (SD) }\end{array}$} & \\
\hline & & & & & \\
\hline & & & & & \\
\hline Re-order point & $\begin{array}{c}4.52(1.19) \\
{[2]}\end{array}$ & $\begin{array}{c}3.39(1.04) \\
{[1]}\end{array}$ & $4.22(1.20)$ & $3.80(1.47)$ & $7.65 * *$ \\
\hline Periodic review & $4.21(1.25)$ & $3.33(1.00)$ & $3.20(2.17)$ & $2.40(0.55)$ & 2.76 \\
\hline Run-out time & $4.53(1.35)$ & $3.83(1.19)$ & $4.75(1.28)$ & $4.18(1.33)$ & 1.64 \\
\hline MRP & $\begin{array}{c}5.14(1.12) \\
{[2,4]} \\
\end{array}$ & $\begin{array}{c}4.12(1.27) \\
{[1]}\end{array}$ & $4.24(1.61)$ & $\begin{array}{c}3.76(1.48) \\
{[1]}\end{array}$ & $7.92 * *$ \\
\hline Kanban & $5.44(1.12)$ & $4.48(1.24)$ & $4.63(1.41)$ & $4.25(1.36)$ & $3.81 * *$ \\
\hline
\end{tabular}

Note: F-statistics are derived from one-way ANOVA. ** indicates significantly different variable on the $\mathrm{p}<0.01$ level. Numbers in brackets [ ] indicate the group numbers with which this group is significantly different at the $\mathrm{p}<0.05$ level. Scheffe's pairwise test of means was used for identifying pairwise differences.

In Section 3.3, high correlations between the perceived performance measures and the objective measures of the relative inventory turnover rate (ITR) and delivery service were identified. Therefore, similar relationships between cluster groups as in Tables 11 and 12 are expected when comparing the "objective performances" between cluster groups. Table 13 shows that the only significant difference between the groups exists for the inventory turnover rate (ITR), where the "Leaders" group has significantly higher ITR compared to all the other groups. No significant difference was identified for delivery service. This is not surprising because materials planning methods control inventories and should have only indirect impact on the delivery service.

Table 13. Inventory turnover rate (ITR) and delivery service by cluster groups

\begin{tabular}{|l|c|c|c|c|l|}
\hline \multirow{2}{*}{ Variables } & \multicolumn{4}{|c|}{ Clusters } & Chi-square \\
\cline { 2 - 5 } & $\begin{array}{c}\text { 1. Leaders } \\
(\mathbf{n}=\mathbf{7 2})\end{array}$ & $\begin{array}{c}\text { 2. Software } \\
\text { reliers (n=43) }\end{array}$ & $\begin{array}{c}\text { 3. Organizers } \\
(\mathbf{n = 2 8})\end{array}$ & $\begin{array}{c}\text { 4. Laggers } \\
(\mathbf{n = 3 5})\end{array}$ & \\
& Mean (SD) & Mean (SD) & Mean (SD) & Mean (SD) & \\
\hline ITR & $\begin{array}{c}4.44(0.76) \\
{[2,4]}\end{array}$ & $\begin{array}{c}3.81(0.92) \\
{[1]}\end{array}$ & $\begin{array}{c}4.07(0.96) \\
{[1]}\end{array}$ & $\begin{array}{c}3.74(0.92) \\
{[1]}\end{array}$ & $8.45^{* *}$ \\
\hline Delivery service & $5.15(0.87)$ & $4.69(1.00)$ & $5.07(1.00)$ & $5.11(1.24)$ & 2.27 \\
\hline
\end{tabular}

Note: F-statistics are derived from one-way ANOVA. ** indicates significantly different variable on the $\mathrm{p}<0.01$ level. Numbers in brackets [ ] indicate the group numbers with which this group is significantly different at the $\mathrm{p}<0.05$ level. Scheffe's pairwise test of means was used for identifying pairwise differences.

User environments among companies with low planning performance

Three groups of method users were studied when comparing the user environments among companies with high and low perceived user friendliness and operational performance. The first group contains those using the re-order point method as their main method. The second group contains those using the re-order point, fixed-order interval or run-out time planning as their main method. These method users were merged into one group because all three methods are working with independent demand and are variants of the re-order point method. The third group contains those using MRP as main method. Two sub-groups were formed for each of the three types of main method users. One sub- 
Full reference: Jonsson, P. (2008). Exploring problems related to the materials planning user environment. International Journal of Production Economics. 113(1): 383-400.

group contained those with low perceived planning performance, and one those with high perceived planning performance.

Table 14 compares the user environment between companies with high and low perceived user friendliness. For re-order point users the lead-time precision, education and knowledge, and software support were the three most critical user-environment issues, with lowest means among users with low perceived user friendliness, and with significantly different means between those with high and low perceived user friendliness. Lead-time precision and education and knowledge are two of the most critical issues for MRP users. Here, management commitment, inventory accuracy and organizational design have more significant impact on the perceived performance, compared to the re-order point users.

Table 14. User environment among companies with low perceived MPC user friendliness

\begin{tabular}{|lcccccc|}
\hline & \multicolumn{2}{c}{ ROP } & \multicolumn{2}{c}{ All ROP } & \multicolumn{2}{c|}{ MRP } \\
& $\begin{array}{l}\text { LUF } \\
(\mathrm{n}=27)\end{array}$ & $\begin{array}{l}\text { HUF-LUF } \\
(\mathrm{n}=25)\end{array}$ & $\begin{array}{c}\text { LUF } \\
(\mathrm{n}=48)\end{array}$ & $\begin{array}{l}\text { HUF-LUF } \\
(\mathrm{n}=52)\end{array}$ & $\begin{array}{c}\text { LUF } \\
(\mathrm{n}=25)\end{array}$ & $\begin{array}{l}\text { HUF-LUF } \\
(\mathrm{n}=66)\end{array}$ \\
& Mean (SD) & Mean & Mean (SD) & Mean & Mean (SD) & Mean \\
\hline Software support & $4.40(2.07)$ & 1.13 & $3.69(1.75)$ & $1.29 *$ & $3.69(1.62)$ & $1.43^{* *}$ \\
Education and knowledge & $3.80(2.28)$ & 0.93 & $3.08(1.80)$ & $1.65^{* *}$ & $2.81(1.60)$ & $1.72^{* *}$ \\
Management commitment & $4.60(1.14)$ & -0.13 & $4.46(1.76)$ & 0.26 & $3.19(1.64)$ & $1.43^{* *}$ \\
Organizational design & $4.20(2.17)$ & 0.20 & $4.23(2.09)$ & 0.60 & $3.44(1.46)$ & $1.49^{* *}$ \\
Available planning time & $4.00(1.87)$ & 0.60 & $3.77(1.96)$ & 0.76 & $3.44(1.90)$ & 0.97 \\
Inventory account accuracy & $3.60(0.89)$ & 0.87 & $4.62(1.66)$ & 0.36 & $3.31(1.85)$ & $1.61^{* *}$ \\
Lead-time precision & $2.80(2.05)$ & $1.93^{*}$ & $2.46(1.71)$ & $2.35^{* *}$ & $2.88(1.71)$ & $1.74^{* *}$ \\
\hline
\end{tabular}

Note: LUF: low performance companies (defines as those with a perceived user friendliness of 1-3 on the 7-point scale), HUF: high performance companies (defined as those with a perceived user friendliness of 57 on the 7 -point scale), ${ }^{*}$ significant $\mathrm{p}<0.05$ (t tests). ${ }^{* *}$ significant $\mathrm{p}<0.01$ (t tests).

Table 15 compares the perceived operational planning performance between the different method users. For the re-order point users, the most critical user-environment issue - and the one that differs most significantly between those with high and low perceived user friendliness - is the lead-time precision. But education and knowledge, available planning time, and the organizational design are also critical and significantly different on the $\mathrm{p}<0.01$ level. The software support, consequently, did not differ significantly between the groups and seems to have a greater impact on the perceived user friendliness than operational performance among the re-order point users. For MRP users, the findings were the same as for perceived user friendliness. Education and knowledge is the most critical issue, but all issues except for the available time and inventory account accuracy differ significantly $(\mathrm{p}<0.05)$ between high and low performers. The fact that inventory account accuracy and lead-time precision do not differ significantly between the groups does not mean that they are not problematic. They are the most problematic variables among firms with high perceived operational performance, indicating that these variables are problematic in all companies. 
Full reference: Jonsson, P. (2008). Exploring problems related to the materials planning user environment. International Journal of Production Economics. 113(1): 383-400.

Table 15. User environment among companies with low perceived operational MPC performance

\begin{tabular}{|c|c|c|c|c|c|c|}
\hline & \multicolumn{2}{|c|}{ ROP } & \multicolumn{2}{|c|}{ All ROP } & \multicolumn{2}{|c|}{ MRP } \\
\hline & $\begin{array}{c}\mathbf{L P} \\
(\mathrm{n}=12)\end{array}$ & $\underset{(n=33)}{\text { HP-LP }}$ & $\underset{(n=19)}{\mathbf{L P}}$ & $\underset{(n=77)}{\mathbf{H P}-\mathbf{L P}}$ & $\begin{array}{c}\mathbf{L P} \\
(\mathrm{n}=18)\end{array}$ & $\underset{(\mathrm{n}=61)}{\mathbf{H P}-\mathbf{L P}}$ \\
\hline & Mean (SD) & Mean & Mean (SD) & Mean & Mean (SD) & Mean \\
\hline Software support & $4.75(1.98)$ & 0.85 & $4.17(1.97)$ & 0.72 & $3.47(1.50)$ & $1.54^{* *}$ \\
\hline Education and knowledge & $3.31(1.78)$ & $2.38 * *$ & $3.27(1.64)$ & $1.53^{* *}$ & $2.84(1.54)$ & $1.59 * *$ \\
\hline Management commitment & $4.44(1.75)$ & 0.76 & $4.17(1.80)$ & 0.83 & $3.11(1.56)$ & $1.64^{* *}$ \\
\hline Organizational design & $3.81(1.98)$ & $1.69 *$ & $4.07(1.98)$ & $1.23^{* *}$ & 3.68 (1.49) & $1.21^{* *}$ \\
\hline Available planning time & $3.06(1.81)$ & $2.64^{* *}$ & $3.53(1.87)$ & $1.29 * *$ & $3.95(1.72)$ & 0.71 \\
\hline Inventory account accuracy & $3.56(1.67)$ & $1.64^{*}$ & $4.40(1.87)$ & 0.89 & $3.79(2.07)$ & 0.16 \\
\hline Lead-time precision & $2.50(1.10)$ & $3.00^{* *}$ & $2.60(1.50)$ & $2.61 * *$ & $3.16(1.57)$ & $1.24^{* *}$ \\
\hline
\end{tabular}

Note: LP: low performance companies (defined as those with a perceived operational planning performance of 1-3 on the 7-point scale), HP: high performance companies (defined as those with a perceived operational planning performance of 5-7 on the 7-point scale), ${ }^{*}$ significant $\mathrm{p}<0.05$ (t tests). ${ }^{* *}$ significant $\mathrm{p}<0.01$ ( $\mathrm{t}$ tests).

\section{Conclusions and comments}

Four distinct clusters of problems related to user environments were identified among materials planning method users. The Leaders are characterized by companies considering all user-environment variables as less problematic, compared to the other three groups, in order for the materials planning methods to work properly. The Laggers consider all user-environment variables as more problematic than do the other four groups. In a third group, Organizers, the way the materials planning is organized, the available time for materials planning, and the inventory account accuracy are considered significantly less problematic compared to all other groups, except for the Leaders. The fourth group, Software reliers, relies heavily on the ERP support when conducting materials planning, and has not invested very much in infrastructural support in terms of management commitment, planning organization, and quality of the basic planning data. This group is mostly represented by companies using MRP to control manufacturing operations. The Laggers and Software reliers have the lowest perceived values of user friendliness and operational performance. For the re-order point users, the Software reliers are the only group with significantly lower perceived operational performance compared to the Leaders.

Consequently, the study shows that purely focusing on software support when conducting materials planning is not enough. It also indicates that a pure software focus may lead to even larger problems compared to not focusing on any of the proposed user-environment characteristics at all. These findings are in line with those of ERP implementations (e.g. Sum, 1999) and AMT usage (e.g. Boyer et al., 1997). A reason for the low perceived performance among Software reliers may be that they do not use analytical strategies when designing methods, and do not work as actively with planning parameter revision as companies in the other environments, especially not compared to the Leaders. The planning environments were almost the same in the four cluster groups. The only difference, that Software reliers and Laggers had more "difficult" order entry characteristics, may explain some of the differences in perceived planning performance. 
Full reference: Jonsson, P. (2008). Exploring problems related to the materials planning user environment. International Journal of Production Economics. 113(1): 383-400.

When comparing the inventory turnover rate, the Leaders showed significantly higher rates than all other groups. This indicates that it should be important to focus on all userenvironment variables (software support, education and knowledge, management commitment, organizational design, available planning time, inventory account accuracy, lead-time precision), as leaders do, in order to have the materials planning methods work properly and result in good operational performance.

When analyzing individual user-environment issues and their role in the materials planning process, it seems that lead-time precision and education and knowledge are the most critical issues for achieving high perceived user friendliness. For the perceived operational performance, all variables are critical; however, education and knowledge together with management commitment and lead-time precision are considered most critical when using MRP, and lead-time precision and education and knowledge when using re-order point methods. The surveyed industries are biased towards MRP usage. A study focusing on lean/JIT environments could probably result in other user environments being most problematic. For example, could the software support be expected to have lower importance in such an environment.

The findings of this study should have direct managerial implications, as they show the perceived planning performance of conducting materials planning in various user environments. They could thus be used as guidelines for developing appropriate environments supporting the materials planning and resulting in improved perceived planning performances. It is important to choose materials planning methods that fit the actual planning environment (characterized by the demand, product and process specifics). This study did not analyze the performance impact of appropriate planning environments compared to user environments, or the combined effect of planning and user environments. In some situations it could, though, be expected that the environment types have varying importance and impact on the perceived planning performance.

Future research can proceed in several directions. Case studies could be conducted in order to better understand the complexity among the user-environment characteristics and how they interact and together affect the perceived planning performance. Survey studies with more detailed user-environment issues would further explain the performance impact of the user environment and also validate the results of this study. In addition, it is important to use the findings of such empirical research studies for developing more normative results, indicating how to create educational programs and planning organizations that support the materials planning usage in appropriate ways.

\section{References}

Andersen, J.A., Jonsson, P., 2006. Does organization structure matter? On the relationship between structure, function and effectiveness, International Journal of Innovation and Technology Management, 3 (3) 237-264.

Berry, W.L., Hill, T., 1992. Linking systems to strategy, International Journal of Operations and Production Management, 12 (10) 3-15. 
Full reference: Jonsson, $P$. (2008). Exploring problems related to the materials planning user environment. International Journal of Production Economics. 113(1): 383-400.

Boyer, K.K., Leong, K.G., Ward, P.T. and Krajewski, L.J., 1997. Unlocking the potential of advanced manufacturing technologies. Journal of Operations Management 15 (4) 331347.

Bozarth, C., 2006. ERP implementation efforts at three firms: integrating lessons from the SISP and IT-enabled change literature, International Journal of Operations and Production Management, 26 (11) 1223-1239.

Braglia, M. and Petroni, A., 1999. Shortcomings and benefits associated with the implementation of MRP packages: a survey research. Logistics Information Management 12 (6) 428-438.

Browne, J., 1996. Production Management Systems: An integrated perspective. Prentice Hall London.

Covin, S., 1981. Inventory accuracy: one of your first hurdles. Production and Inventory Management 22 (2) 13-22.

Gianque, W.C. and Sawaya, W.J., 1992. Strategies for Production Control ", Production and Inventory Management Journal. 33 (3) 36-41.

Hair, J, Anderson, R, Tatham, R, Black, W., 1998. Multivariate data analysis. Prentice Hall London.

Hamilton, S. 2003, Maximizing your ERP system, McGraw-Hill, New York.

Gianque, W.C. and Sawaya, W.J., 1992. Strategies for Production Control. Production and Inventory Management Journal. 33 (3) 36-41.

Jonsson, P., 2000. An empirical taxonomy of advanced manufacturing technology. International Journal of Operations and Production Management 20 (12) 1446-1474.

Jonsson, P. and Mattsson, S-A., 2003. The implication of fit between planning environments and manufacturing planning and control methods. International Journal of Operations and Production Management 23 (8) 872-900.

Jonsson. P. and Mattsson, S-A., 2006. A longitudinal study of materials planning applications in manufacturing companies. International Journal of Operations and Production Management. 26 (9) 971-995.

Jonsson, P. and Mattsson, S-A., 2007. Inventory management practices and their impact on planning performance”, International Journal of Production Research. 1-26.

Krajewski, L., King, B., Ritzman, L. and Wong, D., 1987. "Kanban, MRP and shaping the manufacturing environment”, Management Science, 33 (1) 39-57.

Ling, C. and Goddard, W., 1988. Orchestrating success: improving control of the business with sales and operations planning. John Wiley \& Sons, New York.

Muscatello, J., Small, M., Chen, I., 2003. Implementing enterprise resource planning (ERP) systems in small and midsize manufacturing firms. International Journal of Operations and Production Management 23 (8) 850-871.

Newman, W., and Sridharan, V., 1992. Manufacturing planning and control: Is there one definite answer?. Production and Inventory Management Journal 33 (1) 50-54.

Olhager, J. and Seldin, E., 2004. Supply chain management survey of Swedish manufacturing firms. International Journal of Production Economics 89 353-361. 
Full reference: Jonsson, $P$. (2008). Exploring problems related to the materials planning user environment. International Journal of Production Economics. 113(1): 383-400.

Petroni, A., 2002. Critical factors of MRP implementation in small and medium-sized firms. International Journal of Operations and Production Management 22 (3) 329-348.

Pinjala, S.K, Pintelon, L, Vereecke, A., 2006. An empirical investigation of the relationship between business and maintenance strategy, International Journal of Production Economics, 104 214-229.

Plenert, G., 1999. Focusing Material Requirements Planning (MRP) Towards Performance. European Journal of Operations Research 119 91-99.

Rabinovich, E., Dresner, M., Evers, P., 2003. Assessing the effects of operational processes and information systems on inventory performance. Journal of Operations Management 21 63-80.

Safizadeh, H., Ritzman, L., Sharma, D., Wood, C., 1996. An empirical analysis of the product-process matrix. Management Science 42 (11) 1576-1591.

Safizadeh, H. and Ritzman, L., 1997. Linking performance drivers in production planning and inventory control to process choice. Journal of Operations Management 15 389-403.

Salaheldin, S. and Francis, A., 1998. A study on MRP practices in Egyptian manufacturing companies. International Journal of Operations and Production Management 18 (6) 588-611.

Stadtler, H. and Kilger, C., 2005. Supply chain management and advanced planning. Springer Verlag, Berlin.

Stank, T.P., Daugherty, P.J., Autry, C.W. 1999. Collaborative planning: supporting automatic replenishment programs. Supply Chain Management 14 (2) 75-85.

Sum, C., Quek, S., Lim, H., 1999. Analysing interaction effects on MRP implementation using ACE. International Journal of Production Economics 58 303-318.

Sun, A., Yzdani, A., Overend, J. (2005), Achievement assessment for enterprise resource planning (ERP) system implementation based on critical success factors (CSFs). International Journal of Production Economics 98 189-203.

Turnipseed, D., Burns, O., Riggs, W., 1992. An implementation analysis of MRP systems: a focus on the human variable. Production and Inventory Management Journal 33 (1) 1-6.

Vollmann, Berry, W., Whybark, C, Jacobs, R., 2005. Manufacturing planning and control for supply chain management. McGraw Hill, New York.

White, E., Anderson, J., Schroeder, R., Tupy, S., 1982. A study of the MRP implementation process. Journal of Operations Management 2 (3) 145-153.

Wong, P.-K. and Ngih, P.M., 1997. Automation and organizational performance: the case of electronics manufacturing firms in Singapore. International Journal of Production Economics 52 257-68.

Yu, C-S., 2005. Causes influencing the effectiveness of the post-implementation ERP system. Industrial Management \& Data Systems 105 (1) 115-132. 
Full reference: Jonsson, $P$. (2008). Exploring problems related to the materials planning user environment. International Journal of Production Economics. 113(1): 383-400.

\section{Appendix A}

User-environment measures (all issues are measured on 7-point scales, where " 1 " is “Totally agree” and "7” is “Don't agree at all”.

1. SOFTWARE SUPPORT: The software support for inventory management, available in the ERP system is not good enough to make the materials planning method work properly.

2. EDUCATION AND KNOWLEDGE: The level of education and knowledge for materials planning issues is too low in order for the materials planning method to work properly.

3. MANAGEMENT COMMITMENT: The management commitment to materials planning issues is too low in order for the materials planning method to work properly.

4. ORGANIZATIONAL DESIGN: The structure of the materials planning organization makes it hard for the materials planning method to work properly.

5. AVAILABLE PLANNING TIME: The available time for materials planning is too short and every planner has to take care of too many items in order for the materials planning method to work properly.

6. INVENTORY ACCOUNT ACCURACY: The inventory account accuracy is too low in order for the materials planning method to work properly.

7. LEAD TIME PRECISION: The lead time precision in the basic data file in the ERP system is too low in order for the materials planning method to work properly. 